\title{
Association between Carotid Intima Media Thickness and Measurements of Adiposity among Residents and Interns of a Tertiary Hospital in the Philippines
}

\author{
Maryenka M. Bonode, ${ }^{1}$ Raymund Paul C. Baello² and Jundelle Romulo K. Jalique ${ }^{3}$ \\ ${ }^{1}$ Department of Nutrition, College of Public Health, University of the Philippines Manila \\ ${ }^{2}$ Department of Internal Medicine, VRP Medical Center, Mandaluyong City, Philippines \\ ${ }^{3}$ Department of Epidemiology and Biostatistics, College of Public Health, University of the Philippines Manila
}

\begin{abstract}
Introduction. Atherosclerotic diseases wherein obesity is a risk factor was shown to be the leading causes of mortality according to statistics. Body mass index (BMI), waist hip ratio (WHR) and waist circumference (WC), measurements of adiposity, were consistently identified as good measures of cardio-metabolic health risks. High-resolution B-mode ultrasound measurements of carotid intima-media thickness (CIMT) have also been used as a reliable and reproducible method to detect preclinical atherosclerosis, a precursor of cardiovascular disease.
\end{abstract}

Objective. This study aims to investigate which of the measurements of adiposity would best correlate with early vascular changes primarily noted in the CIMT among non-high risk clinicians of Victor R. Potenciano Medical Center (VRPMC).

Methods. A total of 38 subjects out of 42 residents and interns of VRPMC volunteered to participate in the study from August to November 2010. They had no evidence of cardiac or vascular disease. The weight, height, WC, and hip circumference of each subject were measured. High-resolution B-mode ultrasonography of the right and left common carotid arteries was then performed.

Results. A weak correlation between BMI with CIMT was found. There is no association between WC and WHR and thickness of CIMT.

Conclusion. WC, BMI, and WHR are insignificantly associated with CIMT in this study.

Key Words: Body mass index, waist to hip ratio, waist circumference, carotid intima-media thickness, tertiary hospital

Poster Presented at the 41st Philippine College of Physicians Annual Convention, May 2-4, 2011, SMX Convention Center, Pasay City, Philippines.

Corresponding author: Maryenka M. Bonode, RMT, MD, DPCP

Department of Nutrition

College of Public Health

University of the Philippines Manila

625 Pedro Gil St., Ermita, Manila 1000 Philippines

Telefax no.: +632 5255858

Email: maryenkamd@gmail.com
Introduction

Atherosclerotic diseases wherein obesity is a risk factor have been shown to be leading causes of mortality in a number of statistical studies.1-4 Although clinical manifestations of atherosclerosis do not occur until middle age, the development of vascular changes begins early in life. ${ }^{5}$ In 2001, cerebrovascular diseases accounted for an estimate of 5.5 million deaths worldwide. Around 17 million people have died from cardiovascular disease according to 2008 WHO statistics. The National Center for Health Statistics in the US describe cardiovascular diseases as having accounted for $34.3 \%$ of all causes of death in 2006, translating to 1 of every 2.9 deaths, while cerebrovascular diseases accounted for about 1 of every 18 deaths with a rate of 1 person dying from stroke every 4 minutes. In the Philippines, diseases of the heart and vascular system ranked first and second for leading causes of mortality in $2003 .{ }^{6}$

High-resolution B-mode ultrasound measurements of carotid intima-media thickness (CIMT) have been used as an inexpensive, reliable, and reproducible method to evaluate and detect preclinical atherosclerosis. ${ }^{7}$ Studies have shown that with significant increase in CIMT there is a corresponding increase in risk of cardiovascular and cerebrovascular disease. ${ }^{8}$ Similarly, previous cross-sectional studies have demonstrated that young adults with metabolic syndrome (a combination of risk factors including obesity, impaired glucose tolerance, hypertension and dyslipidemia) have increased CIMT.9,10 This is due to the many significant changes occurring in the arterial wall, including endothelial dysfunction and an increase in intima-media thickness, before the onset of clinical findings, and these changes can be useful in the early diagnosis of atherosclerosis. ${ }^{11-15}$

General and central adiposity which define obesity are rapidly increasing in prevalence not only locally but also globally. Based on DOST-Food and Nutrition Research Institute studies, a rising trend of overweight and obesity has been seen among Filipino adults aged 20 years old and above. Higher than desirable levels of body fat pose an increased risk of ill-health; however, the location of excess fat appears to have particular implications. ${ }^{16,17}$ For example, a greater concentration of adipose tissue in the abdomen, 
specifically in the visceral area, is directly related to metabolic and cardiovascular risk in adults. ${ }^{18}$ Lipid abnormalities are related primarily to the amount of visceral fat as measured by imaging techniques. Nevertheless, not all hospitals have imaging modalities such as ultrasonography, magnetic resonance imaging and $\mathrm{CT}$ scans which can be used in everyday clinical practice. Recent attention has been paid to the applicability of body mass index (BMI) and anthropometric markers to measure central obesity. BMI, waist hip ratio (WHR), and waist circumference (WC) have been consistently identified as good measures of cardiometabolic health risks. ${ }^{19,20}$ Recent studies on subjects with no known vascular events have demonstrated CIMT correlation with BMI and WC..$^{21,22}$

This study aims to investigate which of the measurements of adiposity (BMI, WHR and WC) best correlate with early vascular changes primarily in the thickening of carotid intima-media among residents and postgraduate interns of Victor R. Potenciano Medical Center (VRPMC).

\section{Methods}

\section{Study Population}

A total of 38 subjects out of 42 residents and postgraduate interns, non-gender specific, of VRPMC volunteered to participate in the study from August to November 2010. Thorough histories were taken with an emphasis on comorbidities. These were non-high-risk subjects with no evidence of cardiovascular, cerebrovascular or peripheral vascular disease. The participants had no history of either vascular events or elevations in blood pressure, glucose or total cholesterol to exclude subjects with hypertension, diabetes or hypercholesterolemia, respectively, which could influence vascular changes. None of the subjects were on medication for any other illness or were taking contraceptive pills. Current pregnancy, sudden change in body weight of at least $10 \%$ increase within a month, and a history of drug or alcohol abuse leading to organ damage were also in the exclusion criteria.

The study was conducted according to the Declaration of Helsinki, category III. ${ }^{23}$ All participants were interviewed by the research team and an informed and written consent were taken.

\section{Anthropometric Measurements}

Body weight was determined to the nearest $0.1 \mathrm{~kg}$ by using a standard balance beam, and height was measured to the nearest $0.1 \mathrm{~cm}$ by standard height bar. BMI was calculated by weight in kilograms divided by the square of the height in meters. WC was measured to the nearest $0.1 \mathrm{~cm}$ at the mid-point between the lower rib and the top of the iliac crest with the measurement taken at the end of a normal expiration with the participants standing. WHR was determined to the nearest $0.01 \mathrm{~cm}$ with measurements of the hip circumference $(\mathrm{HC})$ at the largest width over the greater trochanters. Waist and hip circumferences were taken twice by using a standard tape measure.

\section{Ultrasonography}

High-resolution B-mode ultrasonography of the right and left common carotid arteries was performed with a Toshiba Xario Ultrasound System (Figure 1). The subjects were examined in the supine position for a period of 3 to 5 minutes with the head turned slightly to the left and to the right. The common, internal, and external carotid arteries were identified by combined B-mode and color Doppler ultrasound examinations. A careful search was performed to obtain an optimal visualization of the vessel wall demonstrating the typical double lines representing the intima-media layer (Figure 2). Intima-media thickness was defined as the distance between the leading edge interface of the far wall and the leading edge of the median adventitia interface of the far wall with an automated edge-tracking method. Two determinations of the right and the left carotid arteries were performed and these two determinations were then averaged; furthermore, the right and the left carotid artery measurements were averaged and used for analysis (mean CIMT). The measurements were performed by a single operator who was blinded to the study population. Another measurement was taken by a different operator for precision.

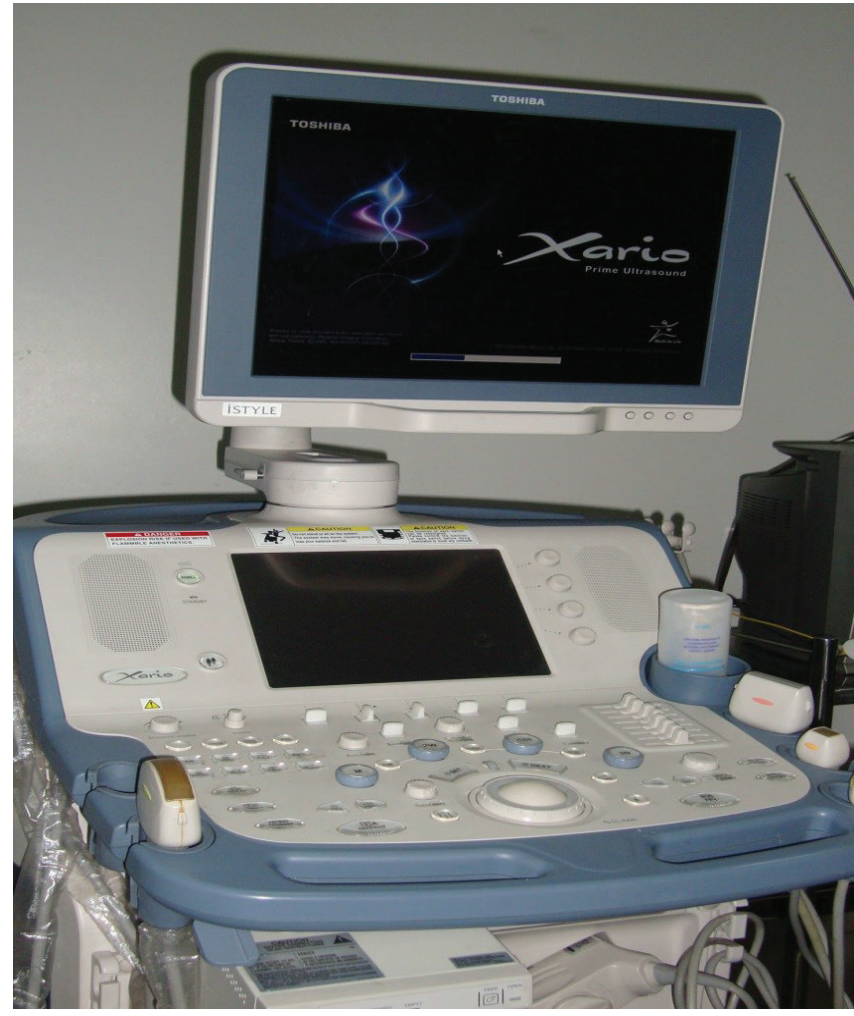

Figure 1. Ultrasound Machine (Toshiba - Xario). 
A moving scan with duration of 5 seconds, which included the beginning of the carotid bifurcation and the common carotid artery, was recorded and stored in digital format on optical disks for subsequent off-line analysis. Digitally stored scans were manually analyzed by a single reader blinded to participants' details, with analyses performed using ultrasonic calipers.

\section{Data Processing and Analysis}

Data was encoded in Microsoft Excel 2010 and analyzed in Stata SE version 12 (Texas, USA). All outcome variables, measurements of adiposity and thickness of carotid intima media, were presented as mean \pm SD. Pearson Product-Moment Correlation was done to measure the correlation between the measures and adiposity and carotid intima-media thickness. Multiple Linear Regression using backward elimination was used to determine the significant predictors of carotid intima-media thickness. Variables with p-values less than 0.05 were considered significant.

\section{Results}

The baseline characteristics of all subjects are outlined in Table 1. Mean age of participants was 30.18 \pm 3.84 years (minimum age is 23 years, maximum age is 39 years). There was a predominance of female participants outnumbering the male participants $>2: 1$. Waist circumference ranges from 61 to $106.7 \mathrm{~cm}$, hip circumference ranges from 81.3 to 101.6 with a mean of $75.78 \pm 9.68 \mathrm{~cm}$ and $90.11 \pm 5.4 \mathrm{~cm}$, respectively. Despite the young age of the study population, IMT levels already showed a substantial variability range $(0.60$ to $1.35 \mathrm{~mm}$ in the right CCA, 0.60 to $1.25 \mathrm{~mm}$ in the left CCA and 0.63 to 1.25 in the average mean IMT).

Across the population studied, waist circumference, and waist to hip ratio showed a plateau line as compared against the mean value of the left and right common carotid arteries signifying almost no relationship (Figures 3, 4).

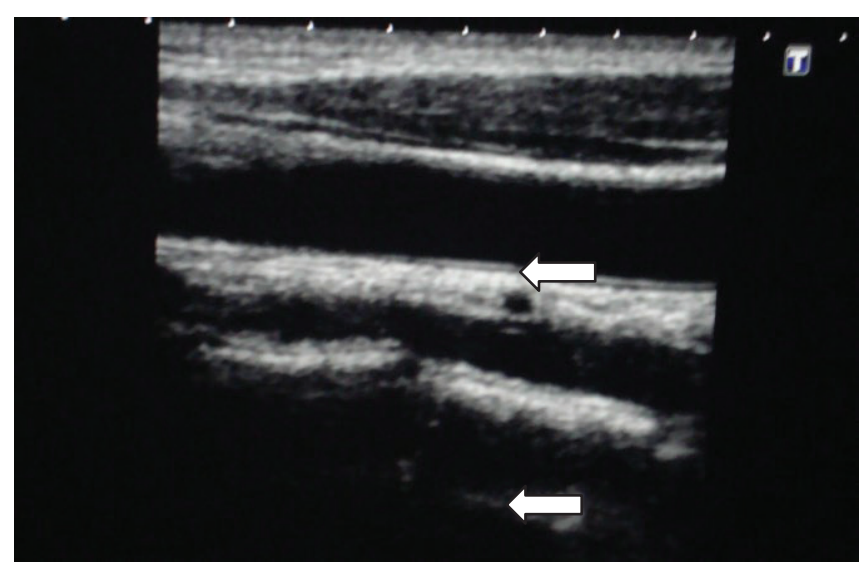

Figure 2. Posterior wall of common carotid artery which shows intima media thickening.

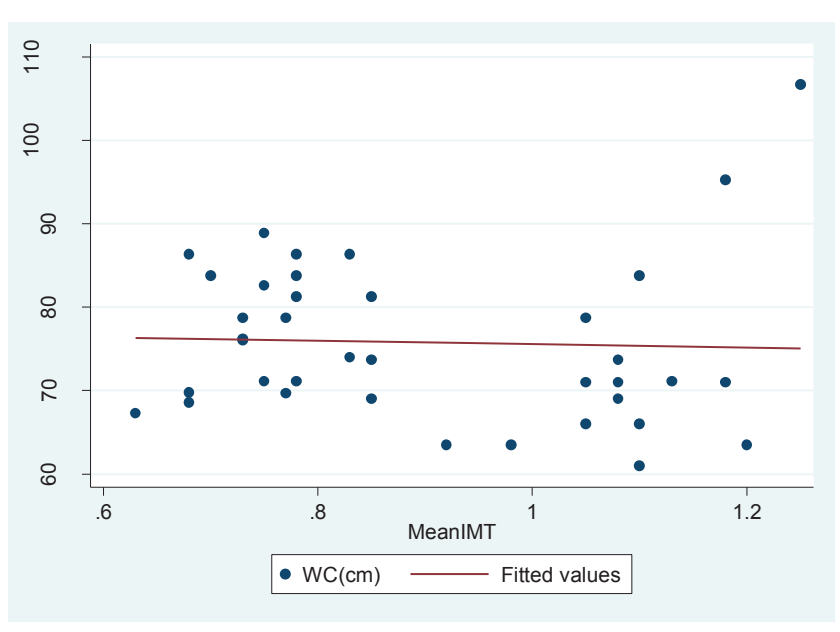

Figure 3. Scatterplot of waist circumference and thickness of intima media.

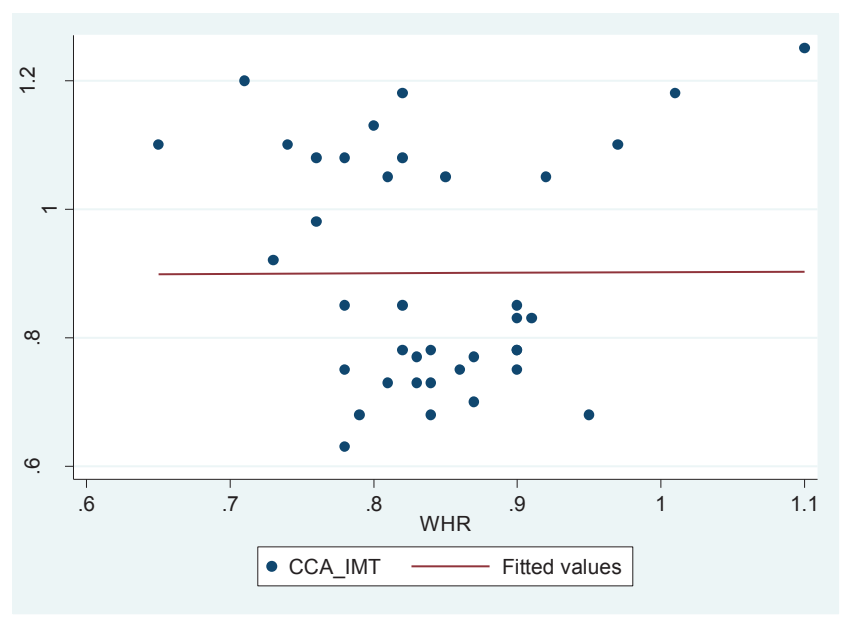

Figure 4. Scatterplot of WHR and thickness of intima media.

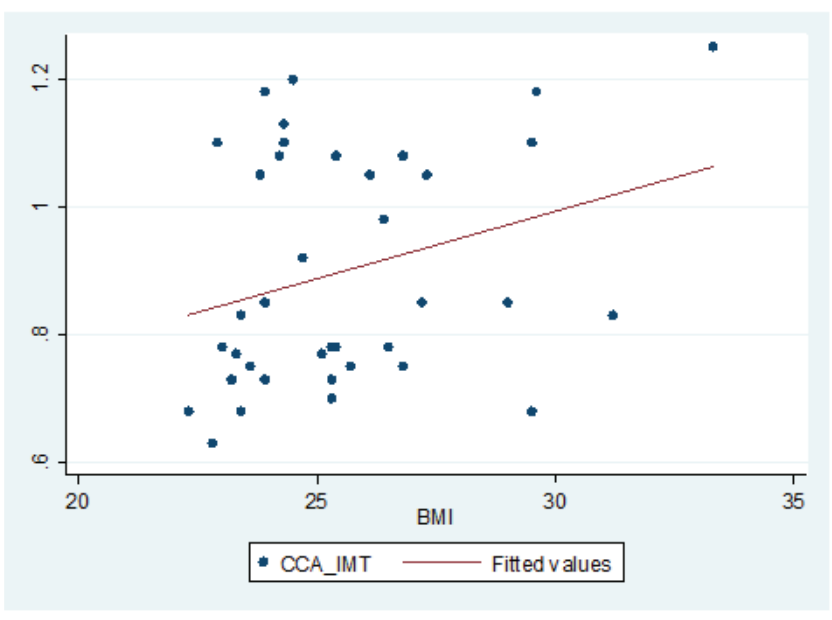

Figure 5. Scatterplot of BMI and thickness of intima media. 
Table 1. Characteristics of Subjects $(n=38)$

\begin{tabular}{lccc}
\hline Variables & Units & Mean \pm SD & Range \\
\hline Age & years & $30.18 \pm 3.84$ years & $23-39$ \\
Sex & & Male 9/ Female 29 & \\
Waist circ. & $\mathrm{cm}$ & $75.78 \pm 9.68$ & $61-106.7$ \\
Hip circ. & $\mathrm{cm}$ & $90.11 \pm 5.4$ & $81.3-101.6$ \\
Weight & $\mathrm{kg}$ & $64.97 \pm 6.68$ & $54-85$ \\
Height & $\mathrm{m}$ & $1.59 \pm 0.07$ & $1.52-1.78$ \\
BMI & $\mathrm{kg} / \mathrm{m}^{2}$ & $25.58 \pm 2.53$ & $22.3-33.3$ \\
Right CCA IMT & $\mathrm{mm}$ & $0.90 \pm 0.19$ & $0.60-1.35$ \\
Left CCA IMT & $\mathrm{mm}$ & $0.90 \pm 0.18$ & $0.60-1.25$ \\
Mean CCA IMT & $\mathrm{mm}$ & $0.90 \pm 0.18$ & $0.63-1.25$ \\
\hline
\end{tabular}

Abbreviations: Waist circ, waist circumference; Hip circ, Hip circumference; BMI,Body Mass Index; CCA, common carotid artery; cm, centimeter; mm, millimeter

Table 2. Summary of Waist Circumference, BMI, WHR, and CIMT

\begin{tabular}{lcl}
\hline & $\begin{array}{c}\text { Mean } \pm \text { SD } \\
\text { [minimum - maximum] }\end{array}$ & Pearson's r \\
\hline Waist circumference $(\mathrm{cm})$ & $75.78 \pm 9.68[61.00-106.70]$ & $-0.17(0.3064)$ \\
Body mass index $\left(\mathrm{Kg} / \mathrm{m}^{2}\right)$ & $25.58 \pm 2.53[22.3-33.3]$ & $0.2911(0.0762)$ \\
Waist-hip ratio $(\mathrm{cm} / \mathrm{cm})$ & $0.84 \pm 0.08[0.65-1.1]$ & $0.0043(0.9794)$ \\
\hline
\end{tabular}

Table 3. Significant Predictors of CIMT

\begin{tabular}{lcc}
\hline & Beta-coefficient & P-value \\
\hline Body mass index $\left(\mathrm{Kg} / \mathrm{m}^{2}\right)$ & 0.022 & 0.050 \\
Sex & -0.152 & 0.022 \\
\hline
\end{tabular}

Whereas, the BMI revealed an increasing line versus the mean value of IMT (Figure 5) signifying that increase in BMI has a corresponding increase in carotid intima media thickness. A summary of the three outcome measures are shown in Table 2.

Based on the results of person product moment correlation, waist circumference and waist hip ratio were not correlated with carotid intima-media thickness, whereas there is a weak correlation between BMI and CIMT. Although some literature presented a relationship between these measures of adiposity and carotid intima-media thickness, the results of this analysis show weak to no relationship partly because of the small sample size.

All possible predictor variables (e.g., age, gender) were then included in the Multiple Regression Analysis. Based on the results, only BMI and gender are considered significant. Accordingly, CIMT increases by 0.022 per $1 \mathrm{~kg} / \mathrm{m}^{2}$ increase in BMI. Also, females' carotid intima media is thicker by 0.152 as compared with males' (Table 3 ).

\section{Discussion}

Several studies have reported a direct relationship of carotid intima-media thickening with multiple risk factors such as hypertension, glucose intolerance, and obesity. Kawamoto et al. noted increase in thickness of IMT was present in other parameters such as age, male gender, and smoking status. ${ }^{24}$
Observations in this study revealed that, in a population of low-risk VRPMC residents and postgraduate interns, there is weak to no association between measurements of adiposity (BMI, waist circumference, and waist hip ratio) and mean common CIMT. Notable in this study is the increase of CIMT by 0.022 per $1 \mathrm{~kg} / \mathrm{m}^{2}$ increase in BMI. A prospective study on 310 middle aged women with no history of cardiovascular events showed a direct correlation of CIMT and waist hip ratio, as well as a corresponding increase of CIMT with a higher BMI. ${ }^{25}$ The results of this study also contradict other prospective cohort findings which correlate BMI and waist circumference with the thickening of carotid intima media.

Previous studies correlating waist circumference and carotid intima-media thickness usually involve subjects with metabolic syndrome. However, in this study the subjects' waist circumference was not limited to be above cut off values according to established criteria as defined by NCEP ATP III criteria.

Little has been reported on association of indices of abdominal obesity and atherosclerosis (i.e. thickening of CIMT) among asymptomatic individuals like that of the sample population in this study. According to a study by Yan et al. on middle-aged men with no known clinical cardiovascular disease, waist hip ratio showed the strongest correlation with CIMT in both univariate and multivariate analyses. $^{26}$

A study on carotid atherosclerosis performed in type 2 diabetic men showed no significant difference between CIMT and waist circumference. In contrast, ultrasonographic measurement of visceral fat thickness showed linear relationship with CIMT regardless of a normal waist circumference. ${ }^{27}$

In a prospective cohort study, BMI along with other cardiovascular risk factors present in adolescence were significantly associated with increased CIMT in adulthood. ${ }^{28}$ A cross-sectional study performed on Greek adolescents showed that mean CIMT was correlated with waist circumference and waist hip ratio. ${ }^{29}$

With regards to differences between cardiovascular measurements, in this case, intima-media thickness, a study done on a Chinese population show that there is no noted difference between sexes in the absence of risk factors. ${ }^{30}$ In subjects from the British Regional Heart Study, it was noted that CIMT in women was thinner compared with men (geometric mean $1.36 \mathrm{~mm}$ versus $1.54 \mathrm{~mm}$ ). Furthermore, CIMT was noted to be linearly and continuously associated with waist-hip ratio across both sexes. ${ }^{31}$ Results in our study showed that the CIMT is thicker by $0.152 \mathrm{~mm}$ in women as compared with males.

The limitation of the study included a small sample size with limited information on confounding factors which may establish a direct relationship of WC, BMI, and WHR with CIMT. 


\section{Conclusion}

The result of the study indicates that there is weak correlation between BMI and CIMT. There is also no association between the other two measurements of adiposity (WC and WHR) and thickness of CIMT. Furthermore, in this study, increase in WC, BMI, and WHR are not risk factors for atherosclerosis among residents and interns of VRPMC.

The authors recommend future studies with larger sample size which may include other health workers within the hospital or individuals from other institutions such as schools and corporations. Confounding factors such as age, gender, and smoking status may be included to establish if there is an association with measurements of adiposity that may influence CIMT. Biochemical risk factor studies including analysis of antioxidants, inflammatory and other biomarkers may also be done in the local population with a younger age group to note their association with ischemia and endothelial dysfunction in the vasculature. 32,33 Finally,ultrasound image analysis of visceral fat may also be correlated with CIMT.

\section{References}

1. Ono T, Guthold R. et al. WHO Global Comparable Estimates [Online]. 2010 [cited 2010 Feb]. Available from www.apps.who.int/infobase/ Comparisons.

2. American Heart Association. Heart Disease and Stroke Statistics - 2005 Update [Online]. [cited 2010 Feb]. Available from www.my.cleveland clinic.org/Documents/heart/1105390918119HDSStats2005Update.pdf

3. Lloyd-Jones D, Adams RJ, Brown TM, et al. Heart Disease and Stroke Statistics-2010 Update: a report from the American Heart Association. Circulation. 2010; 121(7):e46-e215.

4. NCHS Health Data Interactive. Centers for Disease Control and Prevention. Leading Causes of Death Reports 2006 [Online]. 2006 [cited $2010 \mathrm{Feb}$. Available from www.cdc.gov/nchs/data.

5. Koskinen J, Kahonen M, Viikari JS, et al. Conventional cardiovascular risk factors and metabolic syndrome in predicting carotid intima-media thickness progression in young adults: the cardiovascular risk in young Finns study. Circulation. 2009; 120(3):229-36.

6. Dans AL, Morales DD, Velandria F, et al. NNHeS: 2003 Group. National Nutrition and Health Survey (NNHeS): Atherosclerosis - Related diseases and risk factors. Philipp J Intern Med. 2005; 43:103-15.

7. Lofren I, Herron $\mathrm{K}$, Zern $\mathrm{T}$, et al. Waist circumference is a better predictor than body mass index for coronary heart disease risk in overweight premenopausal women. J Nutr. 2004; 134(5):1071-6.

8. Lorenz MW, Markus HS, Bots ML, Rosvall M, Sitzer M. Prediction of clinical cardiovascular events with carotid intima-media thickness: a systematic review and meta-analysis. Circulation. 2007; 115(4):459-67.

9. Tzou WS, Douglas PS, Srinivasan SR, et al. Increased subclinical atherosclerosis in young adults with metabolic syndrome: the Bogalusa Heart Study. J Am Coll Cardiol. 2005; 46(3):457-63.

10. Mattsson N, Ronnemaa T, Juonala M, et al. Arterial structure and function in young adults with the metabolic syndrome: the Cardiovascular Risk in Young Finns Study. Eur Heart J. 2008; 29(6):784-91.

11. Kanters SD, Algra A, van Leeuwen MS, Banga JD. Reproducibility of in vivo carotid intima-media thickness measurements: a review. Stroke. 1997; 28(3):665-71.

12. Kuller L, Borhani N, Furberg C, et al. Prevalence of subclinical atherosclerosis and cardiovascular disease and association with risk factors in the Cardiovascular Health Study. Am J Epidemiol. 1994; 139(12):1164-79.

13. Pignoli P, Tremoli E, Poli A, Oreste P, Paoletti R. Intimal plus medial thickness of the arterial wall: a direct measurement with ultrasound imaging. Circulation. 1986; 74(6):1399-406.
14. O'Leary DH, Polak JF. Intima-media thickness: a tool for atherosclerosis imaging and event prediction. Am J Cardiol. 2002; 90(10C):18L-21L.

15. Ludwig $\mathrm{M}$, von Petzinger-Kruthoff $\mathrm{A}$, von Buquoy $\mathrm{M}$, Stumpe $\mathrm{KO}$. Intima media thickness of the carotid arteries: early pointer to arteriosclerosis and therapeutic endpoint. Ultraschall Med. 2003; 24(3):162-74.

16. Janssen I, Katzmarzyk PT, Ross R. Waist circumference and not body mass index explains obesity-related health risk. Am J Clin Nutr. 2004; 79(3):379-84.

17. Després J-P, Moorjani S, Lupien PJ, Tremblay A, Nadeau A, Bouchard C. Regional distribution of body fat, plasma lipoproteins, and cardiovascular disease. Arteriosclerosis. 1990; 10(4):497-511.

18. Leenen R, van der Kooy K, Seidell JC, Deurenberg P. Visceral fat accumulation measured by magnetic resonance imaging in relation to serum lipids in obese men and women. Atherosclerosis.1992; 94(2-3):171-81.

19. Klein S, Allison DB, Heymsfield SB, et al. Waist circumference and cardiometabolic risk: a consensus statement from Shaping America's Health: Association for Weight Management and Obesity Prevention; NAASO,The Obesity Society; the American Society for Nutrition; and the American Diabetes Association. Am J Clin Nutr. 2007; 85(5):1197-202

20. Paniagua L, Lohsoonthorn V, Lertmaharit S, Jiamjarasrangsi W, Williams M. Comparison of waist circumference, body mass index, percent body fat and other measure of adiposity in identifying cardiovascular disease risks among Thai adults. Obes Res Clin Pract. 2008; 2(3):215-23.

21. Savva SC, Tornaritis M, Savva ME, et al. Waist Circumference and Waist-to-Height Ratio are Better Predictors of Cardiovascular Disease Risk Factors in Children than Body Mass Index. Int J Obes Relat Metab Disord. 2000; 24(11):1453-8.

22. Maher V, O'Dowd M, Carey M, et al. Association of Central obesity with early carotid intima-media thickening is independent of that from other risk factors. Int J Obes. 2009; 33(1):136-43.

23. World Medical Association. Declaration of Helsinki Ethical Principles for Medical Research Involving Human Subjects, 59 th WMA General Assembly, Seoul, October 2008, 1-4.

24. Kawamoto R, Ohtsuka N, Ninomiya D, Nakamura S. Association of obesity and visceral fat distribution with intima-media thickness of carotid arteries in middle-aged and older persons. Intern Med. 2008; 47(3):143-9.

25. De Michele M, Panico S, Iannuzzi A, et al. Association of obesity and central fat distribution with carotid artery wall thickening in middle aged women. Stroke. 2002; 33(12):2923-8.

26. Yan RT, Yan AT, Anderson TJ, et al. The differential association between various anthropometric indices of obesity and subclinical atherosclerosis. Atherosclerosis. 2009; 207(1):232-8.

27. Kim SK, Park SW, Kim SH, Cha BS, Lee HC, Cho YW. Visceral fat amount is associated with carotid atherosclerosis eon type 2 diabetic men with a normal waist circumference. Int J Obes (Lond). 2009; 33(1):131-5.

28. Raitakari OT, Juonala M, Kahonen M, et al. Cardiovascular risk factors in childhood and carotid artery intima media thickness in adulthood (The Cardiovascular Risk in Young Finns Study). JAMA. 2003; 290(17):2277-83

29. Kollias A, Psilopatis I, Karaqiaouri E, et al. Adiposity, blood pressure, and carotid intima-media thickness in Greek adolescents. Obesity (Silver Spring). 2013; 21(5):1013-7.

30. Yao F, Liu Y, Liu D, et al. Sex Differences between vascular endothelial function and carotid intima-media thickness by Framingham Risk Score. J Ultrasound Med. 2014; 33(2):281-6

31. Lawlor D, Ebrahim S, Whincup P, et al. Sex differences in body fat distribution and carotid intima media thickness: cross sectional survey using data from the British Regional Heart Study. J Epidemiol Community Health. 2004; 58(8):700-4.

32. Giannini C, de Giorgis T, Scarinci A, et al. Increased carotid intimamedia thickness in pre-pubertal children with constitutional leanness and severe obesity: the speculative role of insulin sensitivity, oxidant status, and chronic inflammation. Eur J Endocrinol. 2009; 161(1):73-80.

33. Yeban $\mathrm{C}$, Olivar $\mathrm{T}$, et al. Correlation of endothelial dysfunction and inducible ischemia in patients with metabolic syndrome. Philippine Journal of Cardiovascular Medicine. 2006; 17:21-5. 
Appendix: Crude measurements of body mass index, waist hip ratio, waist circumference and B-mode ultrasonographic analysis of common carotid artery intima media thickness

\begin{tabular}{|c|c|c|c|c|c|c|c|c|c|c|}
\hline & Age & $\begin{array}{l}\text { Wt } \\
(\mathrm{kg})\end{array}$ & $\begin{array}{l}\mathrm{Ht} \\
(\mathrm{m})\end{array}$ & $\begin{array}{c}\text { BMI } \\
\left(\mathrm{Kg} / \mathrm{m}^{2)}\right.\end{array}$ & $\begin{array}{l}\text { WC } \\
(\mathrm{cm})\end{array}$ & $\begin{array}{l}\mathrm{HC} \\
(\mathrm{cm})\end{array}$ & $\begin{array}{l}\text { WHR } \\
(\mathrm{cm} / \mathrm{cm})\end{array}$ & $\begin{array}{l}\text { RT CCA IMT } \\
(\mathrm{mm})\end{array}$ & $\begin{array}{l}\text { LT CCA IMT } \\
(\mathrm{mm})\end{array}$ & $\begin{array}{c}\text { Mean CCA IMT } \\
(\mathrm{mm})\end{array}$ \\
\hline 1. $\mathrm{F}$ & 33 & 60 & 1.6 & 23.4 & 74.0 & 81.3 & 0.91 & 0.75 & 0.90 & 0.83 \\
\hline 2. F & 30 & 63 & 1.52 & 27.3 & 71.0 & 83.8 & 0.85 & 1.05 & 1.05 & 1.05 \\
\hline 3. F & 32 & 65 & 1.65 & 23.9 & 71.0 & 86.4 & 0.82 & 1.25 & 1.10 & 1.18 \\
\hline 4. F & 29 & 66 & 1.57 & 26.8 & 71.0 & 91.4 & 0.78 & 1.05 & 1.10 & 1.08 \\
\hline 5. F & 30 & 62 & 1.6 & 24.2 & 69.0 & 83.8 & 0.82 & 1.15 & 1.00 & 1.08 \\
\hline 6. M & 33 & 70 & 1.67 & 29.5 & 83.8 & 86.4 & 0.97 & 1.10 & 1.10 & 1.10 \\
\hline 7. F & 25 & 62 & 1.54 & 26.1 & 66.0 & 81.3 & 0.81 & 1.15 & 0.95 & 1.05 \\
\hline 8. F & 37 & 79 & 1.54 & 33.3 & 106.7 & 101.6 & 1.10 & 1.35 & 1.15 & 1.25 \\
\hline 9. $\mathrm{F}$ & 36 & 60 & 1.57 & 24.3 & 71.1 & 88.9 & 0.80 & 1.10 & 1.15 & 1.13 \\
\hline 10. F & 30 & 71 & 1.55 & 29.6 & 95.3 & 94.0 & 1.01 & 1.10 & 1.25 & 1.18 \\
\hline 11. $\mathrm{F}$ & 34 & 55 & 1.52 & 23.8 & 78.7 & 85.3 & 0.92 & 1.00 & 1.10 & 1.05 \\
\hline $12 . \mathrm{F}$ & 29 & 61 & 1.55 & 25.4 & 86.4 & 96.5 & 0.90 & 0.75 & 0.80 & 0.78 \\
\hline 13. F & 23 & 61 & 1.52 & 26.4 & 63.5 & 83.8 & 0.76 & 1.00 & 0.95 & 0.98 \\
\hline 14. $\mathrm{F}$ & 39 & 60 & 1.57 & 24.3 & 61.0 & 94.0 & 0.65 & 1.10 & 1.10 & 1.10 \\
\hline 15. F & 30 & 58 & 1.54 & 24.5 & 63.5 & 89.0 & 0.71 & 1.25 & 1.15 & 1.20 \\
\hline 16. F & 28 & 60 & 1.62 & 22.9 & 66.0 & 89.0 & 0.74 & 1.10 & 1.10 & 1.10 \\
\hline 17. F & 26 & 65 & 1.6 & 25.4 & 73.7 & 96.5 & 0.76 & 1.00 & 1.15 & 1.08 \\
\hline 18. F & 31 & 61 & 1.57 & 24.7 & 63.5 & 86.4 & 0.73 & 0.85 & 1.00 & 0.92 \\
\hline 19. F & 35 & 69 & 1.65 & 25.3 & 81.3 & 96.5 & 0.84 & 0.75 & 0.80 & 0.78 \\
\hline 20. M & 29 & 67 & 1.7 & 23.2 & 78.7 & 94.0 & 0.84 & 0.70 & 0.75 & 0.73 \\
\hline 21. F & 29 & 55 & 1.57 & 22.3 & 69.8 & 87.9 & 0.79 & 0.65 & 0.70 & 0.68 \\
\hline 22. $\mathrm{M}$ & 27 & 85 & 1.78 & 26.8 & 88.9 & 99.1 & 0.90 & 0.75 & 0.75 & 0.75 \\
\hline 23. F & 36 & 62 & 1.62 & 23.6 & 71.1 & 91.4 & 0.78 & 0.75 & 0.75 & 0.75 \\
\hline 24. M & 30 & 68 & 1.72 & 23.0 & 83.8 & 92.9 & 0.90 & 0.75 & 0.80 & 0.78 \\
\hline 25. M & 34 & 73 & 1.70 & 25.3 & 83.8 & 96.5 & 0.87 & 0.70 & 0.70 & 0.70 \\
\hline 26. M & 24 & 69 & 1.70 & 23.9 & 76.2 & 91.4 & 0.83 & 0.70 & 0.75 & 0.73 \\
\hline 27. F & 37 & 67 & 1.52 & 29.0 & 73.7 & 94.0 & 0.78 & 0.85 & 0.85 & 0.85 \\
\hline 28. F & 29 & 72 & 1.52 & 31.2 & 86.4 & 96.5 & 0.90 & 0.90 & 0.75 & 0.83 \\
\hline 29. F & 32 & 62 & 1.53 & 26.5 & 71.1 & 86.4 & 0.82 & 0.80 & 0.75 & 0.78 \\
\hline 30. M & 27 & 69 & 1.53 & 29.5 & 86.4 & 91.4 & 0.95 & 0.75 & 0.60 & 0.68 \\
\hline 31. F & 25 & 59 & 1.61 & 22.8 & 67.3 & 86.4 & 0.78 & 0.60 & 0.65 & 0.63 \\
\hline 32. F & 30 & 70 & 1.65 & 25.7 & 82.6 & 96.5 & 0.86 & 0.75 & 0.75 & 0.75 \\
\hline 33. F & 28 & 58 & 1.52 & 25.1 & 69.7 & 83.8 & 0.83 & 0.75 & 0.80 & 0.77 \\
\hline 34. F & 27 & 69 & 1.65 & 25.3 & 76.0 & 94.0 & 0.81 & 0.70 & 0.75 & 0.73 \\
\hline 35. F & 30 & 54 & 1.52 & 23.4 & 68.6 & 81.3 & 0.84 & 0.70 & 0.65 & 0.68 \\
\hline 36. F & 26 & 59 & 1.57 & 23.9 & 69.0 & 83.8 & 0.82 & 0.80 & 0.90 & 0.85 \\
\hline 37. M & 29 & 74 & 1.65 & 27.2 & 81.3 & 90.4 & 0.90 & 0.85 & 0.85 & 0.85 \\
\hline 38. M & 28 & 69 & 1.72 & 23.3 & 78.7 & 90.4 & 0.87 & 0.80 & 0.75 & 0.77 \\
\hline
\end{tabular}

Abbreviations: BMI, body mass index; WHR, waist to hip ratio; WC, waist circumference; Wt, weight; Ht, height; RT, right; LT, left; CCA, common carotid artery; IMT, intima media thickness; mm, millimeter; $\mathrm{cm}$, centimeter 